\title{
Introduction to Speculations on Quasi-Experimental Design in HIV/AIDS Prevention Research
}

\author{
Beatrice J. Krauss \\ City University of New York School of Public Health at \\ Hunter College New York, New York
}

Donald T. Campbell was a generous mentor. On the advice of my soonto-be-spouse, Herbert H. Krauss, I took Don's large lecture class in Social Psychology as an undergraduate at Northwestern University in the 1960's, following it with an independent study with him. For the next 30 years, Herb and I kept in contact with Don, reading his writings, attending his presentations when we could, and requesting comments on papers, letters of recommendation and career advice.

In 1990, I was a senior research assistant at Memorial Sloan-Kettering working with Karolyn Siegel, PI, on a cross-sectional, largely qualitative study, of risky sex in gay men who had or had not been tested for HIV. We noted in the transcripts how HIV+ men had faced a set of psychosocial challenges that unfolded with, and paralleled, the natural history of the disease. We drove out to Lehigh to consult with Don on analyses in November 1990. He suggested a quasi-longitudinal study which combined the retrospection of those with AIDS over their disease course with the immediately reported reactions of those who had just experienced diagnosis, of those who were living through the phenomenologically misnamed "asymptomatic" phase where every cold or ache could instill panic, or of those who were in the symptomatic phase where first hospitalizations may have occurred. As with nearly every consultation with Don, a publication resulted: Living with HIV infection: Adaptive tasks of seropositive gay men (Siegel \& Krauss, 1991), followed by two others following down his methodological insights (Siegel, Krauss \& Karus, 1994; Siegel, Raveis \& Krauss, 1992).

It was at our next meeting that Don showed me the revised draft of a paper he had prepared for a National Institute of Health Panel on HIV methodology. My task was to fine tune the paper with regard to HIV, providing real-world HIV-relevant examples where applicable and seeing if I could get some real data-CD-4 count time series, for example. We wrote joint notes on the draft; he scribbled my name next to his and we tried to keep up with the rapidly-changing epidemic until his untimely death in May 1996.

www.avert.org, one of the most highly respected HIV information websites, maintains a timeline of HIV prevalence, as well as treatment and prevention milestones. In the ensuing years these included 
recommendations for early treatment with AZT (1992) and use of AZT to prevent mother-to-child transmission (1992), introduction of the first rapid HIV test (1992), and, in 1996-1997, the landscape-changing introduction of combination or Highly Active Antiretroviral Therapy (HAART).

Impressively, Don Campbell had already taken account of the wide swings in repeated CD-4 counts, the fact that any HIV educational interventions were going to take place against a backdrop of local, community and national messaging (Krauss, Wolitski, Tross, Corby \& Fishbein, 1999) and the selection biases - now referred to as HIV complacency - that would cause people to turn away from intervention.

In editing this draft, I have changed AIDS (which refers only to an advanced stage of a disease, HIV infection) to HIV/AIDS, and added some clarifications from Don's and my joint notes.

For those interested in exemplars relevant to HIV of the various designs Campbell outlines, let me recommend:

\section{Use of administrative records}

Crystal, S., Sambamoorthi, U., Moynihan, P. J. \& McSpiritt, E. (2001). Initiation and continuation of newer antiretroviral treatments among Medicaid recipients with AIDS. Journal of General Internal Medicine, $16,850-859$.

\section{Quasi-experimental assignment of intervention sites}

The CDC AIDS Community Demonstration Projects Research Group. (1999). Community-level HIV intervention in five cities: Final outcome data from the CDC AIDS Community Demonstration Projects. American Journal of Public Health, 89, 336-345. PMCID: 1508588

\section{Random invitation design}

Krauss, B., Godfrey, C., O'Day, J., \& Freidin, E. (2006). Hugging my uncle: The impact of a parent training on children's comfort interacting with persons with HIV. Journal of Pediatric Psychology, 31(9), 891904. PMID: 16452647 Included as an effective program in the metaanalysis by Sengupta, S., Banks, B., Jonas, D., Miles, M.S., Smith, G.C. (2010). HIV interventions to reduce HIV/AIDS stigma: A systematic review. AIDS and Behavior, Epub November 19, 2010, DOI 10.1007/s10461-010-9847 


\section{Quasi-experimental designs in HIV research}

Kessler, R. C. (1993). Quasiexperimental design in AIDS psychosocial research. In D. G. Ostrow \& R. C. Kessler (Eds.), Methodological issues in AIDS behavioral research (pp. 76-92). New York: Plenum.

\section{References}

Krauss, B. J., Wolitski, R. J., Tross, S., Corby, N. H., Fishbein, M., \& the AIDS Community Demonstration Projects. (1999). Getting the message: HIV information sources of women who have sex with injecting drug users - A two site study. Applied Psychology: An International Review, 48, 153-173.

Siegel, K., \& Krauss, B. (1991). Living with HIV infection: Adaptive tasks of seropositive gay men. Journal of Health and Social Behavior, 32, 17-32.

Siegel, K. S., Krauss, B. J., \& Karus, D. (1994). Reporting recent sexual practices: Gay men's disclosure of risk by questionnaire and interview. Archives of Sexual Behavior, 23, 217-230.

Siegel, K. S., Raveis, V. H., \& Krauss, B. J. (1992). Factors associated with urban gay men's treatment initiation decisions for HIV infection. AIDS Education and Prevention, 4, 135-142. 